\title{
Bias Literacy for Gender Equity: A Brief Intervention
}

\author{
Carol Isaac, Joseph Balloun, Tracey Wofford \\ Department of Educational Leadership, Mercer University, Atlanta, Georgia, USA \\ Email: isaac_ca@mercer.edu
}

How to cite this paper: Isaac, C., Balloun, J., \& Wofford, T. (2020). Bias Literacy for Gender Equity: A Brief Intervention. Open Journal of Social Sciences, 8, 59-71. https://doi.org/10.4236/jss.2020.86006

Received: April 8, 2020

Accepted: May 29, 2020

Published: June 3, 2020

Copyright $\odot 2020$ by author(s) and Scientific Research Publishing Inc. This work is licensed under the Creative Commons Attribution International License (CC BY 4.0).

http://creativecommons.org/licenses/by/4.0/

\section{(c) (i) Open Access}

\begin{abstract}
Although higher education promotes the advancement of women, the number of women in executive leadership positions has remained stagnant over the last decade. Research has suggested that gender inequity frequently arises from implicit or unconscious bias. This mixed-methods study illustrates the results of a 1-hour bias literacy workshop that provided strategies to mitigate unconscious bias for 67 graduate students, including K-12 and higher education administrators. Results demonstrated significant pre-post differences for the Perceived Constraints Scale $(p=.05)$ which suggested that one month after the workshop, participants still perceived greater constraints with implicit bias and decision-making. Qualitative findings indicated that participants reported increased awareness because of the use of the implicit association test, illustrating Stage 2 (Contemplation) within Prochaska's Stages of Change model. This study suggests that the strategies provided by this brief workshop are important for future interventions regarding implicit bias.
\end{abstract}

\section{Keywords}

Bias Literacy, Implicit Bias, Intervention, Training, Mixed Methods

\section{Introduction}

Although companies promote programs to advance women, the number of women in executive leadership has remained stagnant over the last decade (Wynn \& Correll, 2018). There are numerous articles depicting the leaky pipeline for women in masculine fields, including leadership (Good et al., 2008; Justice, 2009; Kaatz \& Carnes, 2014). Pew Research reported that women hold only $10 \%$ of the top positions in U.S. companies in 2017 and only 5.1\% of CEO's of S\&P 1500 companies (DeSilver, 2018).

Research has rejected the suggestion that fewer women enter the pipeline or 
are less committed to careers (National Academy of Engineering, 2006). Instead, research has suggested that gender inequity arising from implicit bias or frequently unconscious bias creates the greatest barriers in leadership (Carnes, Devine, Baier Manwell, Byars-Winston et al., 2015; Isaac et al., 2009). These biases are ingrained into society's cultural fabric and these differentiated gendered responses are habitual (Devine et al., 2012).

\section{Literature Review}

Prejudiced behaviors occur via unconscious (implicit) cognitive mechanisms that often contradict individual's conscious (explicit) beliefs (Devine, 1989, 2001). Devine (1989) further described these implicit mechanisms as "habits of mind." Explicit bias may be deliberately expressed and controlled (Greenwald \& Banaji, 1995); however, implicit actions are automatically activated implicitly (Greenwald et al., 1998). Devine (1989) contended that stereotypes influence an individual's judgment about others and this judgment can be unconscious.

Studies have used the Implicit Association Test (IAT) to help increase the awareness of implicit bias (Carnes, Devine, Baier Manwell, Byars-Winston et al., 2015; Dasgupta \& Asgari, 2004; Devine et al., 2012). While there has been some controversy regarding the validity of this test, research indicates that the IAT is predictive of the prevalence of mental processes of automatic and unconscious behaviors (Chugh, 2004; Greenwald et al., 1998; Nosek et al., 2009). This dual categorization task increases the motivation to change, and measures the strength of association between multiple attributes (i.e. race, weight, age, sexuality) (Nosek et al., 2011). One research study demonstrated the predictive validity of the IAT for managers' egalitarian efforts with interactions with others and their decision-making processes (Chugh, 2004). In the current study, the Gender-Career IAT established to participants their association between gendered names and career and family.

Research suggests that brief interventions can mitigate implicit bias in individuals (Carnes, Devine, Baier Manwell, Byars-Winston et al., 2015; Devine et al., 2012). Carnes and colleagues $(2012,2015)$ suggest specific strategies to mitigate bias including stereotype replacement, counter-stereotype imaging, individuating, perspective-taking, and increasing opportunities for contact. Stereotype replacement recognizes that a personal response is stereotypical and then replacing it with nonstereotypical response (Devine et al., 2012). Counter-stereotype imaging involves imaging positive exemplars, for example an effective woman leader either in abstract or a personal connection (Blair et al., 2001). Individuation prevents stereotypic inaccurate assumptions by gathering specific details, focusing on the personal rather than a general evaluation of a group category of an individual (Heilman, 1984). Perspective taking involves increasing the psychological closeness of someone in a marginalized group, mitigating automatic group associations (Galinsky \& Moskowitz, 2000). Increasing opportunities for contact with exemplars of out-group members alters cognitive mechanisms by 
improving group evaluations (Allport et al., 2015; Pettigrew et al., 2011). Even with knowledge of these strategies, active learning is needed to evoke change (Boonyasai et al., 2007), and learning requires reflection with practice (Behar-Horenstein et al., 2009). With a commitment to change, practice is required to initiate new habitual behavior (Plant \& Devine, 2009).

Bias literacy is a prerequisite for action and was a term first used by Sevo and Chubin (2008). A Bias Literacy Workshop, which furnishes opportunities for participants to engage in self-reflection and critical thinking, "adheres to the tenets of an effective group process" and intentional behavioral change and has been implemented to raise awareness of bias (Carnes et al., 2012: p. 66). Prochaska and DiClemente (1983) created a framework describing behaviors for five "stages of change" where individuals transcend from negative to positive behaviors. They include pre-contemplation, contemplation, preparation, action, and maintenance. Initially healthcare professionals developed this model for smoking cessation, and the model was further developed for applications to gender equity and advancement (Isaac et al., 2012; Prochaska et al., 2006; Prochaska et al., 2001). "Pre-contemplation" in terms of gender equity denies that personal bias exists. "Contemplation" is where participants increase their awareness of individual and professional bias. "Preparation" consists of participants describing plans to change or have taken "action" to change. The last stage, "Maintenance," identifies actions taken for more than six months.

This paper is a description of a brief form of a bias literacy workshop, initially spearheaded at the University of Wisconsin-Madison as a workshop lasting 2.5 hours (Carnes et al., 2012; Carnes, Devine, Baier Manwell, Byars-Winston et al., 2015). From observational research of critical incidents occurring between participants (Isaac, 2016), the workshop was shortened to one hour. The research question for this study is, will there be a statistically significant difference in participants' personal mastery, perceived constraint and leadership self-efficacy scores after the participation of a bias literacy workshop, and will the qualitative data reflect Prochaska's Stages of Change model?

\section{Methods}

The Institutional Review Board (IRB) at Mercer University approved this study. The workshop activities included taking the gender-career implicit association test (IAT) on Harvard's Project Implicit website (Nosek et al., 2011), research regarding discrimination, implicit bias characteristics, bias malleability and strategies to mitigate implicit bias (Carnes, Devine, Baier Manwell, Sheridan et al., 2015; Isaac, 2016). Participants engaged in a quantitative pretest-posttest design (Field, 2013) with open-ended questions utilizing mixed methods (QUAN $\rightarrow$ qual) to determine whether this workshop raised awareness of the role of bias within participants' experiences. Reasons for mixed methods (QUAN $\rightarrow$ qual) include triangulation and validity, where the qualitative findings ask clarifying questions to expand the breath of the study (Greene et al., 1989; Hesse-Biber \& 
Nagy Leavy, 2011).

This workshop was presented at an annual leadership conference for 2015, 2016 and 2017, and in graduate introductory research courses in 2018. All participants were graduate students, scholar educators or administrators from a large urban area in the southeast United States. Over the four-year period, 67 participants attended the workshop and completed the post-tests, 23 males and 44 females; and 50 graduate students, 16 post-graduates and one undergraduate (professional status). After the participants completed their informed consent, they took three written self-administered questionnaires regarding psychological well-being (Lachman \& Weaver, 1998). Psychological well-being was divided into two subdomains including Perceived Mastery (Cronbach's $\alpha=.73$ ) and Perceived Constraints (Cronbach's $\alpha=.86$ ). A leadership self-efficacy questionnaire also was included (Cronbach's $\alpha=.90$ ) (Hoyt \& Blascovich, 2007: p. 601). After the workshop, they also completed evaluations and commitment to change statements that research shows and improves retention (Lockyer et al., 2001). Demographic data included gender and professional status. Post-tests given one month later included the questionnaires and open-ended questions that included "What do you remember from the workshop?" and "Can you recall any incidents since the workshop where you saw evidence in practice?" Previous research used this combination of questionnaires (Carnes et al., 2012). Analysis included both descriptive and inferential statistics to analyze the quantitative results using SPSS, and deductive thematic content analysis to analyze the responses from the open-ended questions and workshop evaluations (Boyatzis, 1998; Grbich, 2013). We used NVivo for data retrieval and organization. The two types of data collected provided triangulation for this study, and peer review and debriefing occurred through discussions between the investigators (Glesne, 2015).

\section{Results}

\subsection{Workshop Evaluation}

Of the 67 participants that attended, 39 (58\%) completed hardcopy evaluation forms immediately after the workshop. Of these evaluations, $88 \%$ ranked the quality of content at least at a " 4 " and $25(64 \%)$ of these scored it at a " 5 " or "excellent" then 93\% rated the relevance of the topic at least at a "4" with 23 (54\%) scoring it at a "5." Of importance, $45 \%$ ranked the usefulness of the topic at their workplace at least at a " 4 " with $33 \%$ giving it a " 5 ," and $45 \%$ also scored the increase in content knowledge at least at a " 4 " with $38 \%$ ranking at a "5." The commitment to change responses from 39 participants indicated that $87 \%$ planned to implement at least one strategy at work and $77 \%$ planned to do so at home. Strategies that were the most referenced were "counter-stereotypic imaging," "individuating," and "stereotype replacement." Only three of the participants did not complete the gender-science IAT according to the evaluations.

In past research, the IAT results did not show any change after the interven- 
tion (Carnes, Devine, Baier Manwell, Byars-Winston et al., 2015) so the IAT pre-tests were not collected but used to raise "awareness" of bias.

\subsection{Quantitative Results}

Of the 67 participants that attended, 26 (39\%) completed the post-test one month after the workshop. After entering data into SPSS, analysis included both descriptive and inferential statistics using repeated measures $t$ tests to analyze the differences between the pretest and posttest group responses. Cronbach's alpha was computed to estimate the internal consistency of the measures for comparison to the established values (Table 1 ).

There were differences in the mean scores for the Personal Mastery Scale (pretest $M=1.64$, posttest $M=1.73$ ) Perceived Constraints Scale (pretest $M=$ 5.58 , posttest $M=6.00$ ) and the Leadership Self-Efficacy Scale (pretest $M=2.02$, posttest $=M=1.96$ ) $($ Table 2$)$. The Kolmogorov-Smirnov test demonstrated that the pretest and posttest scale distributions were not normally distributed except for Leadership Self-efficacy Posttest (Table 3). Correlations were done between gender and professional status and the dependent scales of mastery, constraint, and leadership scales. Graduate versus post-graduate status but not gender were correlated with one or more of the dependent scales (Table 4).

Group statistics (Table 5) and a multivariate-test (Table 6) were done for graduate versus post graduate participants. A multivariate model indicated a main effect for the Perceived Constraints Scale (Wilkes lambda ( $p=.01 ; \eta p 2$ $=.26)$ ). In this model the interaction with professional status was not significant $(p=.08 ; \eta p 2=.13)$. A simple t-test confirmed significance for the Perceived Constraints Scale $(p=.01)$ (Table 7).

Table 1. Cronbach's alpha for current study.

\begin{tabular}{ccccc}
\hline Scales & Occasion & Cronbach's Alpha & Cronbach's Alpha Based on Standardized & Number of Items \\
\hline \multirow{2}{*}{ Personal Mastery Scale } & Pre & .48 & .50 & 4 \\
& Post & .48 & .50 & .84 \\
Perceived Constraints Scale & Pre & .83 & .84 & 8 \\
& Post & .83 & .93 & 8 \\
Leadership Self-Efficacy & Pre & .92 & .69 & 8 \\
& Post & .65 &
\end{tabular}

Table 2. Descriptive statistics pre- vs. posttest results.

\begin{tabular}{ccccc}
\hline Survey & Pre- v. Posttest & $S D$ & $N$ & $M$ \\
\hline \multirow{2}{*}{ Personal Mastery } & Pre & .78 & 26 & 1.64 \\
Perceived Constraints & Post & .53 & 26 & 1.73 \\
Leadership Self-Efficacy & Pre & 1.03 & 26 & 5.58 \\
& Post & .78 & 26 & 6.00 \\
& Pre & .74 & 26 & 2.02 \\
\hline
\end{tabular}


C. Isaac et al.

Table 3. Kolmogorov-smirnov (KS) tests of normality.

\begin{tabular}{|c|c|c|c|}
\hline Survey & Pre- v. Posttest & KS D Statistic & Significance \\
\hline \multirow{3}{*}{ Personal Mastery } & Pre & .15 & .001 \\
\hline & & & \\
\hline & Post & .26 & .001 \\
\hline \multirow[b]{2}{*}{ Perceived Constraints } & Pre & .15 & .001 \\
\hline & Post & .22 & .002 \\
\hline \multirow[t]{2}{*}{ Leadership Self-Efficacy } & Pre & .19 & .001 \\
\hline & Post & .14 & .20 \\
\hline
\end{tabular}

Table 4. Correlation results.

\begin{tabular}{|c|c|c|c|c|c|c|c|c|c|}
\hline & Gender & Graduate & Postgraduate & Mastery_Pre & Mastery_Post & Constraints_Pre & $\begin{array}{c}\text { Constraints } \\
\text { _Post }\end{array}$ & Leadership & _Pre Leadership_Post \\
\hline Gender & 1.00 & .08 & -.05 & .04 & .07 & .12 & $.26^{*}$ & .11 & .24 \\
\hline Graduate & & 1.00 & $-.96^{* *}$ & $-.25^{*}$ & .00 & .11 & $-.40^{*}$ & $.26^{*}$ & $.32^{*}$ \\
\hline Postgraduate & & & 1.00 & $.28^{*}$ & .01 & -.14 & $.40^{*}$ & -.24 & $-.32^{*}$ \\
\hline Mastery_Pre & & & & 1.00 & -.02 & -.08 & -.04 & .01 & .09 \\
\hline Mastery_Post & & & & & 1.00 & -.11 & -.04 & .09 & .24 \\
\hline Constraints_Pre & & & & & & 1.00 & .37 & -.23 & -.19 \\
\hline Constraints_Post & & & & & & & 1.00 & -.18 & -.29 \\
\hline Leadership_Pre & & & & & & & & 1.00 & $.76^{* *}$ \\
\hline Leadership_Pos & & & & & & & & & 1.00 \\
\hline
\end{tabular}

Table 5. Group statistics for graduate versus post graduate participants.

\begin{tabular}{|c|c|c|c|c|}
\hline Survey & Pre- v. Posttest & & $M$ & $S D$ \\
\hline & Pre & Graduate & 1.76 & .55 \\
\hline \multirow[t]{4}{*}{ Personal Mastery } & & Post-Grad & 2.30 & 1.37 \\
\hline & Post & Graduate & 1.71 & .49 \\
\hline & & Post-Grad & 1.71 & .67 \\
\hline & Pre & Graduate & 5.67 & .89 \\
\hline \multirow[t]{3}{*}{ Perceived Constraints } & & Post-Grad & 5.36 & 1.33 \\
\hline & Post & Graduate & 5.84 & .83 \\
\hline & & Post-Grad & 6.52 & .32 \\
\hline \multirow[t]{4}{*}{ Leadership Efficacy } & Pre & Graduate & 2.35 & 1.04 \\
\hline & & Post-Grad & 1.82 & .49 \\
\hline & Post & Graduate & 2.07 & .82 \\
\hline & & Post-Grad & 1.55 & .35 \\
\hline
\end{tabular}


Table 6. Paired samples statistics.

\begin{tabular}{|c|c|c|c|}
\hline Survey & Pre- v. Posttest & Mean & $S D$ \\
\hline \multirow{2}{*}{ Personal Mastery } & Pre & 1.64 & .78 \\
\hline & Post & 1.73 & .53 \\
\hline \multirow{2}{*}{ Perceived Constraints } & Pre & 5.58 & 1.03 \\
\hline & Post & 6.00 & .78 \\
\hline \multirow[t]{2}{*}{ Leadership Self-Efficacy } & Pre & 2.02 & .74 \\
\hline & Post & 1.96 & .75 \\
\hline
\end{tabular}

Table 7. Pretest and Posttest t-test results.

\begin{tabular}{cccc}
\hline & $t$ & $d f$ & $\begin{array}{c}\text { Significance } \\
(2 \text {-tailed })\end{array}$ \\
\hline Personal Mastery & -.46 & 25 & .65 \\
Perceived Constraints & -2.06 & 25 & .05 \\
Leadership Self-Efficacy & .62 & 25 & .54 \\
\hline
\end{tabular}

\subsection{Qualitative Results}

Of the 67 responses, the 26 (39\%) of participants that completed the post-test also completed the two open-ended questions. The questions included: "What do you remember from the workshop?" and "Can you recall any incidents since the workshop where you saw the evidence in practice?" The content thematic analysis used Prochaska's five Stages of Change as the framework for deductive analysis as used and contextualized in a previous study (Isaac et al., 2012). None of the participants denied that bias existed so no text was coded in Stage 1: pre-contemplation. However, the following narrative illustrates the results of the other stages.

Two participants stated that they did not remember anything from the workshop, and one responded "What workshop?" None of the participants could name specific strategies presented in the workshop. However, 15 out of 26 participants specifically reported remembering their results from the IAT, consistent with Stage 2: contemplation. The participants described the workshop as "a very enlightening experience" specifically their reaction to taking the IAT. One participant was "disturbed but also inspired to be more aware of my bias." Taking the IAT was:

Owning my score (:)) - I always thought that I was open to all, yet, I am not. My background has still molded me, despite the educated liberalism of my upbringing. (...) The workshop has made my "box" of knowledge rearrange and grow. This is uncomfortable, yet freeing!

For several participants, they reframed this discomfort into a positive experience. Only nine of the 26 participants could think of a specific incident as one recounted, "While I do not recall a concrete example, I am more aware of the presence of this bias around me at all times." Participants seemed to accept their 
IAT results because the workshop stressed the ubiquity of bias without "finger-pointing" (Isaac et al., 2016). One participant reflected on her relief, "understanding that my implicit bias is part of me and yet malleable."

There were few illustrations of the other stages. One participant described a future action (Stage 3: preparation) nonspecifically with "we can work to change [stereotypes] or adapt to them by identifying them and working around them." For Stage 4, the action stage, one participant reflected,

I tend to notice bias on a daily basis; however, instead of being judgmental, I find myself fascinated with the background to comments-why would they say that? Where did that assumption come from? It is becoming like a treasure hunt, (...) spotting skewed thinking.

This was an example of the strategy of "individuating" from the workshop where participants learned not to make snap decisions based on a stereotype (Carnes et al., 2012; Carnes, Devine, Baier Manwell, Byars-Winston et al., 2015). Another participant could not identify the construct, but could describe the implementation.

I have been much more aware of what words I use in meetings and importantly where I interact with students. We had a great discussion with a small student group about gender bias, which surprised me as the kids come from very conservative Christian families, yet showed me a desire to step aside from prejudice.

Not only did this participant take action by changing her use of language (stereotype replacement), but also initiated a discussion about bias with her students.

Finally, only one participant illustrated Stage 5: maintenance (action over six or more months. She had routinely taken the IAT and other implicit bias trainings over the course of her professional life:

Every day I have to remind myself in my job to set aside implicit biases-men should be strong, mothers with multiple children and no means to support them, alcoholics/drug users, mental illness etc. I make conscious effort to recognize my own biases, think about them, and then set them aside.

This participant demonstrated the strategy of stereotype replacement and perspective taking, the practice of replacing stereotypic thoughts and taking the perspective of others.

\section{Discussion}

Implicit bias is an important topic in the United States and finding evidenced-based interventions is critical (Chapman et al., 2013; Green et al., 2007). The results of the nonparametric test demonstrated statistical significance between the pretest and posttest results for the Perceived Constraints Scale. The 
increase in the mean indicates to the extent participants believe that there are obstacles out of one's control that create barriers to reaching goals (Lachman \& Weaver, 1998). In conjunction, the qualitative findings indicate that participants had increased awareness of their own bias, Stage 2: contemplation (Prochaska et al., 2006). The results of this intervention suggest that the IAT and the workshop influenced participants' perceptions; at least that they are more aware of how bias effected their decision-making.

The qualitative results illustrated that the IAT seemed to have the most effect on participants' perspectives of bias, although the workshop itself perhaps served to buffer their negative responses. The workshop evoked strong some reactions including statements of remorse but also awareness of bias. While the IAT seemed to be what participants remembered, their reaction to that promoted active learning (Mezirow, 1990). Previous research indicated that the IAT serves as a tool that demonstrates that implicit bias is not of malicious intent but is inherent in both genders (Isaac et al., 2016). This realization serves as a neutralizing effect that diminishes defensiveness, a critical element that can reduce backlash toward diversity initiatives (Ng \& Wiesner, 2007; Rosen \& Mericle, 1979; Windscheid et al., 2016).

Previous research has shown that this intervention led to positive changes in perceptions of department climate, the valuing of women's research, and promoting individual needs (Carnes, Devine, Baier Manwell, Byars-Winston et al., 2015). This study lends evidence that having participants take the IAT in conjunction with a brief workshop that unpacks the IAT may be a successful intervention for implicit bias. This study's limitations include the lack of longitudinal data and the analysis did not control for data collection across multiple cohorts, although this probably would have improved the significance in other constructs. In addition, knowing the ethnicity of participants might have provided different perspectives, although this demographic was not included due to the sensitive nature of the topic. The 58 percent response rate for evaluations was obtained because hard copies were immediately available after the workshop. This was much better than the 39 percent of post-tests completed; however, both exceeded an average response rate of 30\% (Creswell, 2014).

Despite limitations, other research suggests that short bias literacy interventions can mitigate implicit bias (Carnes, Devine, Baier Manwell, Byars-Winston et al., 2015; Devine et al., 2012). While this workshop provided little evidence of later stages of change, it is important that educators understand that the first mechanism for change is awareness (Carnes et al., 2012; Prochaska et al., 2006). This research contributes to supporting evidence that a brief workshop can provide bias literacy. The significance of this work centers around the fact that as women continue to enter leadership roles, evidence-based strategies are needed to prevent and understand the activation of implicit bias.

\section{Acknowledgements}

We thank graduate students at Tift College of Education at Mercer University 
for their willingness to participate in this study and examine their implicit bias.

\section{Conflicts of Interest}

The authors declare no conflicts of interest regarding the publication of this paper.

\section{References}

Allport, G. W., Clark, K., \& Pettigrew, T. F. (2015). The Nature of Prejudice. New York: Basic Books.

Behar-Horenstein, L. S., Schneider-Mitchell, G., \& Graff, R. (2009). Promoting the Teaching of Critical Thinking Skills through Faculty Development. Journal of Dental Education, 73, 665-675.

Blair, I. V., Ma, J. E., \& Lenton, A. P. (2001). Imagining Stereotypes Away: The Moderation of Implicit Stereotypes through Mental Imagery. Journal of Personality and Social Psychology, 81, 828-841. https://doi.org/10.1037/0022-3514.81.5.828

Boonyasai, R. T., Windish, D. M., Chakraborti, C., Feldman, L. S., Rubin, H. R., \& Bass, E. B. (2007). Effectiveness of Teaching Quality Improvement to Clinicians: A Systematic Review. The Journal of the American Medical Association, 298, 1023-1037. https://doi.org/10.1001/jama.298.9.1023

Boyatzis, R. E. (1998). Transforming Qualitative Information: Thematic Analysis and Code Development. New York: Sage Publications.

Carnes, M., Devine, P. G., Baier Manwell, L., Byars-Winston, A., Fine, E., Ford, C. E., Forscher, P., Isaac, C., Kaatz, A., Magua, W., Palta, M., \& Sheridan, J. (2015). The Effect of an Intervention to Break the Gender Bias Habit for Faculty at One Institution: A Cluster Randomized, Controlled Trial. Academic Medicine, 90, 221-230. https://doi.org/10.1097/ACM.0000000000000552

Carnes, M., Devine, P., Baier Manwell, L., Sheridan, J., Ford, C., Byars-Winston, A., Isaac, C., Fine, E., \& Nelson Savoy, J. (2015). Breaking the Bias Habit: A Workshop to Pro mote Gender Equity. Madison, WI: WISELI \& the University of Wisconsin-Madison.

Carnes, M., Devine, P., Isaac, C., Baier Manwell, L., Ford, C., Byars-Winston, A., Fine, E., \& Sheridan, J. (2012). Promoting Institutional Change through Bias Literacy. Journal of Diversity in Higher Education, 5, 63-77. https://doi.org/10.1037/a0028128

Chapman, E., Kaatz, A., \& Carnes, M. (2013). Physicians and Implicit Bias: How Doctors May Unwittingly Perpetuate Health Care Disparities. Journal of General Internal Medicine, 28, 1504-1510. https://doi.org/10.1007/s11606-013-2441-1

Chugh, D. (2004). Societal and Managerial Implications of Implicit Social Cognition: Why Milliseconds Matter. Social Justice Research, 17, 203-222. https://doi.org/10.1023/B:SORE.0000027410.26010.40

Creswell, J. (2014). Research Design: Qualitative, Quantitative, and Mixed Methods Approaches (4th ed.). New York: SAGE Publications.

Dasgupta, N., \& Asgari, S. (2004). Seeing Is Believing: Exposure to Counter Stereotypic Women Leaders and Its Effect on the Malleability of Automatic Gender Stereotyping. Journal of Experimental Social Psychology, 40, 642-658.

http://www.sciencedirect.com/science/article/B6WJB-4C40SH8-1/1/38e92a4213d14193 e589d378556bc2a2 https://doi.org/10.1016/j.jesp.2004.02.003

DeSilver, D. (2018). Women Scarce at Top of U.S. Business-and in the Jobs That Lead There. Pew Research. 
http://www.pewresearch.org/fact-tank/2018/04/30/women-scarce-at-top-of-u-s-busine ss-and-in-the-jobs-that-lead-there/

Devine, P. G. (1989). Stereotypes and Prejudice: Their Automatic and Controlled Components. Journal of Personality and Social Psychology, 56, 5-18. https://doi.org/10.1037/0022-3514.56.1.5

Devine, P. G. (2001). Implicit Prejudice and Stereotyping: How Automatic Are They? Introduction to the Special Section. Journal of Personality and Social Psychology, 81, 757-759. https://doi.org/10.1037/0022-3514.81.5.757

Devine, P. G., Forscher, P. S., Austin, A. J., \& Cox, W. T. L. (2012). Long-Term Reduction in Implicit Race Bias: A Prejudice Habit-Breaking Intervention. Journal of Experimental Social Psychology, 48, 1267-1278. https://doi.org/10.1016/j.jesp.2012.06.003

Field, A. (2013). Discovering Statistics: Using IBM SPSS Statistics (4th ed.). New York: Sage.

Galinsky, A. D., \& Moskowitz, G. B. (2000). Perspective-Taking: Decreasing Stereotype Expression, Stereotype Accessibility, and in-Group Favoritism. Journal of Personality and Social Psychology, 78, 708-724. https://doi.org/10.1037/0022-3514.78.4.708

Glesne, C. (2015). Becoming Qualitative Researchers: An Introduction (2nd ed.). Oxford: Longman.

Good, C., Aronson, J., \& Harder, J. A. (2008). Problems in the Pipeline: Stereotype Threat and Women's Achievement in High-Level Math Courses. Journal of Applied Developmental Psychology, 29, 17-28. https://doi.org/10.1016/j.appdev.2007.10.004

Grbich, C. (2013). Qualitative Data Analysis: An Introduction (2nd ed.). New York: Sage.

Green, A., Carney, D., Pallin, D., Ngo, L., Raymond, K., Lezzoni, L., \& Banaji, M. (2007). Implicit Bias among Physicians and Its Prediction of Thrombolysis Decisions for Black and White Patients. Journal of General Internal Medicine, 22, 1231-1238.

https://doi.org/10.1007/s11606-007-0258-5

Greene, J. C., Caracelli, V. J., \& Graham, W. F. (1989). Toward a Conceptual Framework for Mixed-Method Evaluation Designs. Educational Evaluation \& Policy Analysis, 11, 255-274. https://doi.org/10.3102/01623737011003255

Greenwald, A. G., \& Banaji, M. R. (1995). Implicit Social Cognition: Attitudes, Self-Esteem, and Stereotypes. Psychological Review, 102, 4-28.

https://doi.org/10.1037/0033-295X.102.1.4

Greenwald, A. G., McGhee, D. E., \& Schwartz, J. L. K. (1998). Measuring Individual Differences in Implicit Cognition: The Implicit Association Test. Journal of Personality and Social Psychology, 74, 1464-1480. https://doi.org/10.1037/0022-3514.74.6.1464

Heilman, M. E. (1984). Information as a Deterrent against Sex Discrimination: The Effects of Applicant Sex and Information Type on Preliminary Employment Decisions. Organizational Behavior \& Human Performance, 33, 174-186. https://doi.org/10.1016/0030-5073(84)90019-9

Hesse-Biber, S., \& Nagy Leavy, P. (2011). The Practice of Qualitative Research (2nd ed.). New York: Sage.

Hoyt, C. L., \& Blascovich, J. (2007). Leadership Efficacy and Women Leaders' Responses to Stereotype Activation. Group Processes \& Intergroup Relations, 10, 595-616. https://doi.org/10.1177/1368430207084718

Isaac, C. (2016). Difficult Dialogues: Negotiating Faculty Responses to a Gender Bias Literacy Training Program. The Qualitative Report, 21, 1243-1265.

Isaac, C., Kaatz, A., Lee, B., \& Carnes, M. (2012). An Educational Intervention Designed to Increase Women's Leadership Self-Efficacy. CBE Life Sciences Education, 11, 307-322. 
https://doi.org/10.1187/cbe.12-02-0022

Isaac, C., Lee, B., \& Carnes, M. (2009). Interventions that Affect Gender Bias in Hiring: A Systematic Review. Academic Medicine, 84, 1440-1446. https://doi.org/10.1097/ACM.0b013e3181b6ba00

Isaac, C., Manwell, L. B., Devine, P. G., Ford, C., Byars-Winston, A., Fine, E., Sheridan, J. T., \& Carnes, M. (2016). Difficult Dialogues: Faculty Responses to a Gender Bias Literacy Training Program. Qualitative Report, 21, 1243-1265.

Justice, A. C. (2009). Leaky Pipes, Faustian Dilemmas, and a Room of One's Own: Can We Build a More Flexible Pipeline to Academic Success? Annals of Internal Medicine, 151, 818-819. https://doi.org/10.7326/0003-4819-151-11-200912010-00013

Kaatz, A., \& Carnes, M. (2014). Stuck in the out-Group: Jennifer Can't Grow up, Jane's Invisible, and Janet's over the Hill. Journal of Women's Health, 23, 481-484. https://doi.org/10.1089/jwh.2014.4766

Lachman, M. E., \& Weaver, S. L. (1998). The Sense of Control as a Moderator of Social Class Differences in Health and Well-Being. Journal of Personality and Social Psychology, 74, 763-773. https://doi.org/10.1037/0022-3514.74.3.763

Lockyer, J. M., Fidler, H., Ward, R., Basson, R. J., Elliott, S., \& Toews, J. (2001). Commitment to Change Statements: A Way of Understanding How Participants Use Information and Skills Taught in an Educational Session. Journal of Continuing Education in the Health Professions, 21, 82-89. https://doi.org/10.1002/chp.1340210204

Mezirow, J. (1990). How Critical Reflection Triggers Transformative Learning. In J. Mezirow (Ed.), Fostering Critical Reflection in Adulthood: A Guide to Transformative and Emancipatory Learning (pp. 1-20). New York: Jossey-Bass Publishers.

National Academy of Engineering (2006). Beyond Biases and Barriers: Fulfilling the Potential of Women in Academic Science and Engineering.

Ng, E., \& Wiesner, W. (2007). Are Men Always Picked over Women? The Effects of Employment Equity Directives on Selection Decisions. Journal of Business Ethics, 76, 177-187. https://doi.org/10.1007/s10551-006-9266-3

Nosek, B. A., Banaji, M. R., \& Greenwald, A. G. (2011). Project Implicit. Harvard. http://www.projectimplicit.net/index.php

Nosek, B. A., Smyth, F. L., Sriram, N., Lindner, N. M., Devos, T., Ayala, A., Bar-Anan, Y., Bergh, R., Cai, H., Gonsalkorale, K., Kesebir, S., Maliszewski, N., Neto, F., Olli, E., Park, J., Schnabel, K., Shiomura, K., Tulbure, B. T., Wiers, R. W., Somogyi, M., Akrami, N., Ekehammar, B., Vianello, M., Banaji, M. R., \& Greenwald, A. G. (2009). National Differences in Gender-Science Stereotypes Predict National Sex Differences in Science and Math Achievement. Proceedings of the National Academy of Sciences, 106, 10593-10597. https://doi.org/10.1073/pnas.0809921106

Pettigrew, T. F., Tropp, L. R., Wagner, U., \& Christ, O. (2011). Recent Advances in Intergroup Contact Theory. International Journal of Intercultural Relations, 35, 271-280. https://doi.org/10.1016/j.ijintrel.2011.03.001

Plant, E. A., \& Devine, P. G. (2009). The Active Control of Prejudice: Unpacking the Intentions Guiding Control Efforts. Journal of Personality and Social Psychology, 96, 640-652. https://doi.org/10.1037/a0012960

Prochaska, J. M., Mauriello, L. M., Sherman, K. J., Harlow, L., Silver, B., \& Trubatch, J. (2006). Assessing Readiness for Advancing Women Scientists Using the Transtheoretical Model. Sex Roles, 54, 869-880. https://doi.org/10.1007/s11199-006-9053-8

Prochaska, J. M., Prochaska, J. O., \& Levesque, D. A. (2001). A Transtheoretical Approach to Changing Organizations. Administration and Policy in Mental Health, 28, 
247-261. https://doi.org/10.1023/A:1011155212811

Prochaska, J. O., \& DiClemente, C. C. (1983). Stages and Processes of Self-Change of Smoking: Toward an Integrative Model of Change. Journal of Consulting and Clinical Psychology, 51, 390-395. https://doi.org/10.1037/0022-006X.51.3.390

Rosen, B., \& Mericle, M. F. (1979). Influence of Strong Versus Weak Fair Employment Policies and Applicant's Sex on Selection Decisions and Salary Recommendations in a Management Simulation. Journal of Applied Psychology, 64, 435-439. https://doi.org/10.1037/0021-9010.64.4.435

Sevo, R., \& Chubin, D. E. (2008). Bias Literacy: A Review of Concepts in Research on Discrimination.

Windscheid, L., Bowes-Sperry, L., Kidder, D. L., Cheung, H. K., Morner, M., \& Lievens, F. (2016). Actions Speak Louder than Words: Outsiders' Perceptions of Diversity Mixed Messages. The Journal of Applied Psychology, 101, 1329-1341. https://doi.org/10.1037/apl0000107

Wynn, A. T., \& Correll, S. J. (2018). Combating Gender Bias in Modern Workplaces. In B. Risman, C. Froyum, \& W. Scarborough (Eds.), Handbook of the Sociology of Gender. New York: Springer. https://doi.org/10.1007/978-3-319-76333-0_37 